\title{
Defining typological process in the transformation of Turkish houses
}

\author{
Duygu Gokce, Fei Chen \\ Liverpool School of Architecture, Leverhulme Building, University of Liverpool. UK \\ E-mail: duygu.gokce@bath.edu, fei.chen@liverpool.ac.uk
}

\begin{abstract}
Typological process, defined by the Italian Typological School as 'progressive differentiation' among types in a cultural area is a key terminology in morphological studies. It was widely acknowledged that the identification of typological process is problematic for three reasons. First, the judgement on the degree to which the transformation of types is determined continuous is largely subject to individual researchers' opinions. Second, there is no agreement on the exact typological characteristics that are considered in the transformation process. Third, there is limited empirical studies on typological process at articulated scales. This paper aims to bridge these gaps and contribute to the methodological advancement of defining typological process through an empirical study of the transformation of Turkish houses. Eight housing developments from five morphological periods of Ankara since the late 19th century is examined at the building, street and neighbourhood scales. A typological frame involving a set of spatial characteristics defining the types is established at each scale. According to the number of changes in typological characteristics, continuity, partial continuity and mutation are identified, of which the former two categories of transformation are determined as typological process.
\end{abstract}

Keywords: Typological process, continuity, mutation, type, typological frame, morphological period, culture area, transformation, housing evolution

\section{Introduction}

Typological process refers to progressive changes of types that are widespread in the cultural area and show continuous adaptations to the changing human needs. It has been adopted as one of the theories of change by the Italian School and it is a key concept in Urban Morphology because it bridges between the analysis of the old forms and the design of the new forms (Moudon, 1994; Gauthiez, 2004). It can be established through a comparison of a series of types during their historical evolution where the dominant one replaces the another through the gradual chances undergone by the first one (Caniggia and Maffei, 2001; Gauthiez, 2004). Typological process is thus a tool to ex- plain how the built environment changes and what are the causes underlying these changes (Kropf, 2006). Therefore, it can also help to reveal the robustness of historical types or characteristics for contemporary use. For this reason, various scholars advocated the benefit of continuity in urban transformation for sociocultural sustainability by recycling the robust historical types in contemporary design (Chen \& Thwaites, 2013; Gokce \& Chen, 2016; 2017; Rapoport, 1969; Lynch, 1960; Alexander, et al., 1977; Kropf, 2009; Moudon, 1994).

However, defining typological process has always been found challenging (Whitehand et al., 2014). This is initially because there is no clarity how to determine what continuous transformation is; therefore, the judgement is 
largely subject to individual researchers' opinions (Gokce, 2017). Moreover, there is no consensus regarding the data selection and validity in terms of what spatial characteristics and hierarchies should be detected for continuity (Scheer, 2016). Furthermore, this vagueness in the study of spatial characteristics also causes the ambiguity in the way of differentiating the different place scales in the study of typological process. Such studies are currently limited and generally not empirically grounded, although transformation of types has been studied by various scholars at individual scales or limited levels of specificity (e.g. Gygax, 2007; Oliveira et al., 2015). In addition, there is a need to empirically test the applicability of concept of typological process and clarify its definitions in non-European context (Whitehand et al., 2014).

Given the problems mentioned above, this paper attempts to demonstrate a methodological advancement to define the typological process. The following will therefore first briefly review the theory of typological process, accordingly explain the stages to define typological process at the building, street and neighbourhood scales. The study will then define the typological process in the Turkish context by tracing the transformation of house types since the late 19th century in Ankara. Conclusion will be drawn on the practicality and applicability of the framework in other contexts.

\section{Typological process and its fundamentals}

Italian School defines typological process as the temporal robustness of a type over a period of time in a given cultural context (Caniggia \& Maffei, 2001). It is the process of designing the new types, characteristics of which are gradually adapted from the previous types. Typological process is thus observed during the changes occurred between "the base type" and "the mature type" (Kropf, 1993, p. 96). It is identified by generating a typology relating one type to the other at a chosen scale (e.g. the building, the parcels, the city block) and according to selected typlogical frame setting the criteria for the comparison of the types (e.g. volume, function, density, architectural style)
(Moudon 1994). The built form consists of constant and changeable elements (Rapoport, 1969, p. 81). As a result of the study of these elements at a certain place scale, typological process is constructed through the identification of the constant ones over periods of time in a cultural area. Given these, there are four common concepts the studies of typological process that needs to consider: [1] a series of types, [2] typological frame (and the study scales), [3] time span (morphological periods/phases), and [4] the specific location/cultural area.

A series of types are the key in the study of typological process so that continuous or mutational changes are recognised. Types are determined according to the possession of a certain set of mutual features observed in architectural and urban spaces at a certain scale (Chen \&Thwaites, 2013; Gokce, 2017). There are synchronic and diachronic types (Caniggia and Maffei, 2001). The former refers to the types, the production of which decreases over a period of time and remain strictly to the period it was introduced but can be observed in different places, while the latter undergoes a series of progressive changes for a significant period of time in the same place (Burkay, 2006). The typological process is relevant to diachronic types where the modified type evolves by keeping the essential characteristics of the previous type.

Typological frame outlines a set of physical characteristics through which the types are defined and typological process is constructed according to their comparison at a given place scale. The transformation of types has been studied mainly in relation to the spatial characteristics of layouts of buildings (e.g. Corsini, 1997; Dufaux, 2000; Oliveira et al., 2015), streets (e.g. Ryan, 2006), plots and blocks (e.g. Corsini, 1997; Ryan, 2006; Oliveira et al., 2015). Although there is no consensus regarding exact elements defining spatial typologies, the commonly analysed spatial features in such studies are spatial configuration, functional zoning, building height to street width ratio, density and land coverage, public-private area relations and access patterns, hierarchy and connectivity and open space design.

Time span is vital to construct typological process since it is the time period during which 
a type transforms and becomes mature and therefore a long time interval is necessary for changes of types to be sufficiently clear (Caniggia and Maffei 2001). Conzen (1960) explains this widely accepted notion in the field of urban morphology with the concept of 'morphological periods' each of which refers some turning points in the design concepts of built environment under the influence of internal and external factors (Chen \& Thwaites, 2013).

Cultural area is also key to define typological process because it delimits the territories or context within which types are generated, adapted, transformed or disappeared. Types within the same cultural areas are often affected by the same internal and external factors such as social, political, cultural and economic changes. In other words, types emerged and changed under specific factors that are distinct to a given location (Chen \& Thwaites, 2013).

\section{The study of typological process}

The studies of typological process have begun over half a century ago, with the studies of $\mathrm{Mu}-$ ratori (1960) and Conzen (1960), but the term was used for the first time in 1970s by Caniggia (1976) (Whitehand et al., 2014). To date, the studies have attempted to document the transformation process of the built forms and identify changes in the newer forms from the older ones in different cultural contexts (e.g. Dufaux, 2000; Gu et al., 2008; Whitehand et al., 2014; Maretto \& Scardigno, 2016). Some studies further stress the importance of reconstructing typological process and suggest that new forms should adopt robust types or their characteristics (e.g. Corsini, 2007; Gygax, 2007; Racine 2016). These studies aim to benefit design practice especially in the area of conservation through proposed design guidelines for new intervention (e.g. Gygax, 2007; Barke, 2011; Racine 2016).

From the 2000s, typological process has been investigated at multiple scales and specificities, from the room level to the urban level. Studies examined the spatial configuration and room arrangements (e.g. Corsini, 1997; Gygax, 2007; Gu et al., 2008; Oliveira et al., 2015; Ma- retto \& Scardigno, 2016); as well as the building-building, building-plot, building-street relations (e.g. Ryan 2006; Gygax, 2007; Feng, 2014; Oliveira et al., 2015; Racine, 2016), density and land use (e.g. Ryan, 2006; Gygax, 2007), and spatial sequence from public to private (e.g. Oliveira et al., 2015). These studies showed a vast variety in terms of physical characteristics considered in scholars' work.

Recent studies have tried to explain the transformation patterns and changes in morphological periods (e.g. Dufaux, 2000, Whitehand et al., 2014; Racine, 2016; Maretto \& Scardigno, 2016). However, very few studies investigated the degree of changes in detail amongst a series of types, of which some can be defined as typological process. For example, Racine (2016) attempted to compare a set of morphological components to identify typological relationships between present and past developments and he called these relationships weak, medium, and strong. Based on these relations, this research intended to determine what characteristics should be continued and what should not in future design. Although it was a limited attempt and the defined relations were not directly associated with the typological process, it can inspire the studies of typological process regarding its empirical validation and measurement.

The review of relevant literature showed that typological process is a widely-acknowledged notion in the understanding of the complexities embedded in the structure of the built environment and the city as a spatio-temporal system (Kropf, 1993). However, there is a lack of consensus in the ways of probing degrees of continuous transformation that qualifies typological process. The problem lies in the ambiguity in its definition and the lack of empirical validation in reconstructing the typological process and uncovering its mechanism (Whitehand et al., 2014). In addition, there is also no consistency in what elements, at what scales should be studied. For these reasons, "the precise nature of the typological process remains elusive" (Whitehand et al., 2014). 


\section{How to define typological process?}

In the light of the above reviewed literature and identified key concepts, this study suggests that the typological process can be defined in three stages.

Firstly, a series of types are chosen as case studies that are representative to their specific morphological periods which are identified via the general study of the history of the cultural area in question. In this study, eight housing developments are chosen representing the transformation process of Turkish houses during five morphological periods from the late Ottoman Empire period (the late 19th century) to the present in Ankara.

Secondly, a typological frame is set up through which the chosen case studies are analysed at a given place scale. In this study, the types are identified at the three place scales: building, street and neighbourhood. Table 1 shows the typological frame consisting of a set of spatial characteristics through which types are defined at the three scales in this study.

Thirdly, the types are compared pairwise at the three scales [between the types within the same morphological period and between the types in the different morphological periods] in a chronological order to identify the typological process during their transformation. In this research, three degrees of changes are considered namely continuity, partial continuity or mutation, which are relative to the numbers of changed physical characteristics and the first two of which are considered typological process.

\section{Case selection}

Ankara -located in the northwest of central Anatolia and with a long history dated back to pre-historic times - has been chosen as the study area. Ankara is an important city to study the housing transformation not only because of its geo-morphological structure playing an important role in the city formation but also due to being a new administrative and political centre after the proclamation of the Republic of Turkey in 1923, where the housing efforts were thus primarily applied before any other cities in the country. Starting from the late Ottoman Empire period (1890s to 1923) to the contemporary period (2000s), there are five morphological periods identified in the development history of housing in Ankara. Representing specific topological, socio-cultural, political and functional requirements in each morphological period, eight housing developments are chosen by the authors. Table 2 summaries the key features of the development history of houses during these five periods and briefly introduces the chosen cases studied from each morphological period.

In the late Ottoman empire period, the dominant house types were the traditional Turkish houses which had already developed for hundreds of years following the spatial demand of the nomadic lifestyle of Turkish people before they settled in Anatolia. The development of these house types is mainly traced according to the location of rooms and a hall. The most common types and the still existing ones are the types with interior hall (Case I) and with

\begin{tabular}{|c|c|c|}
\hline BUILDING SCALE & STREET SCALE & NEIGHBOURHOOD SCALE \\
\hline FUNCTIONAL ZONING & ARRANGEMENT OF BUILDINGS ALONG THE \\
STREET & SITE/BLOCK ARRANGEMENT \\
SPATIAL SEQUENCE & $\begin{array}{c}\text { BUILNTRANCES } \\
\text { CHANGES/NUMBER OF TURNS }\end{array}$ & BLOCK SIZE AND SHAPE \\
INTERNAL ACCESS PATTERN/COMPACTNESS & STREET FORM, WIDTH \\
CONNECTIVITY/INTEGRATION & SCTIVE FRONT COVERAGE SEQUENCE \\
VISIBILITY & HEIGHT/WIDTH & BUILDING HEIGHT/SPACIOUSNESS \\
PERMEABILITY & SPATIAL HIERACHY & LAND COVERAGE \\
& SISUAL ACCESSIBITY & STREET CONFIGURATION \\
\hline
\end{tabular}

Table 1: Typological frame defined at the three scales 


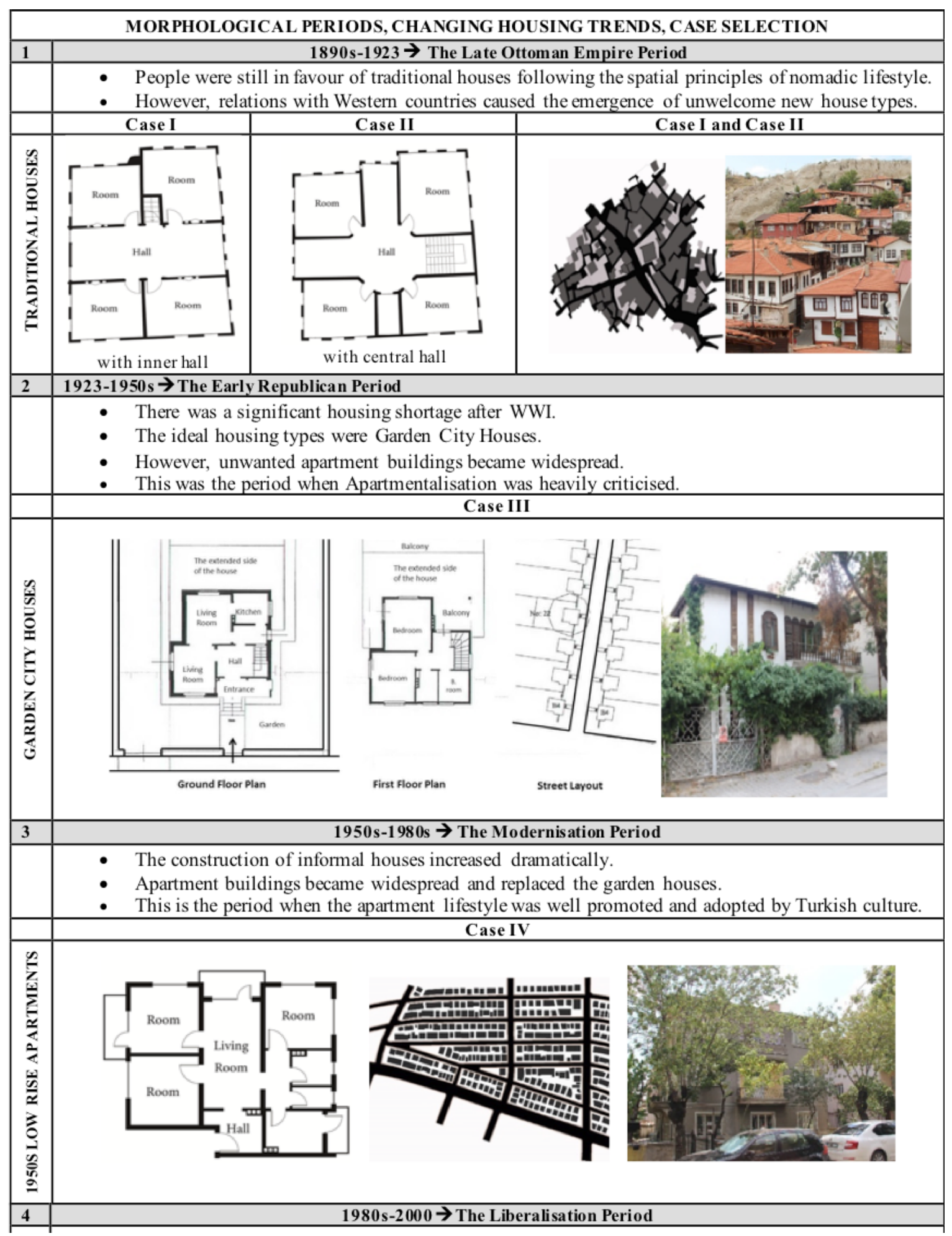




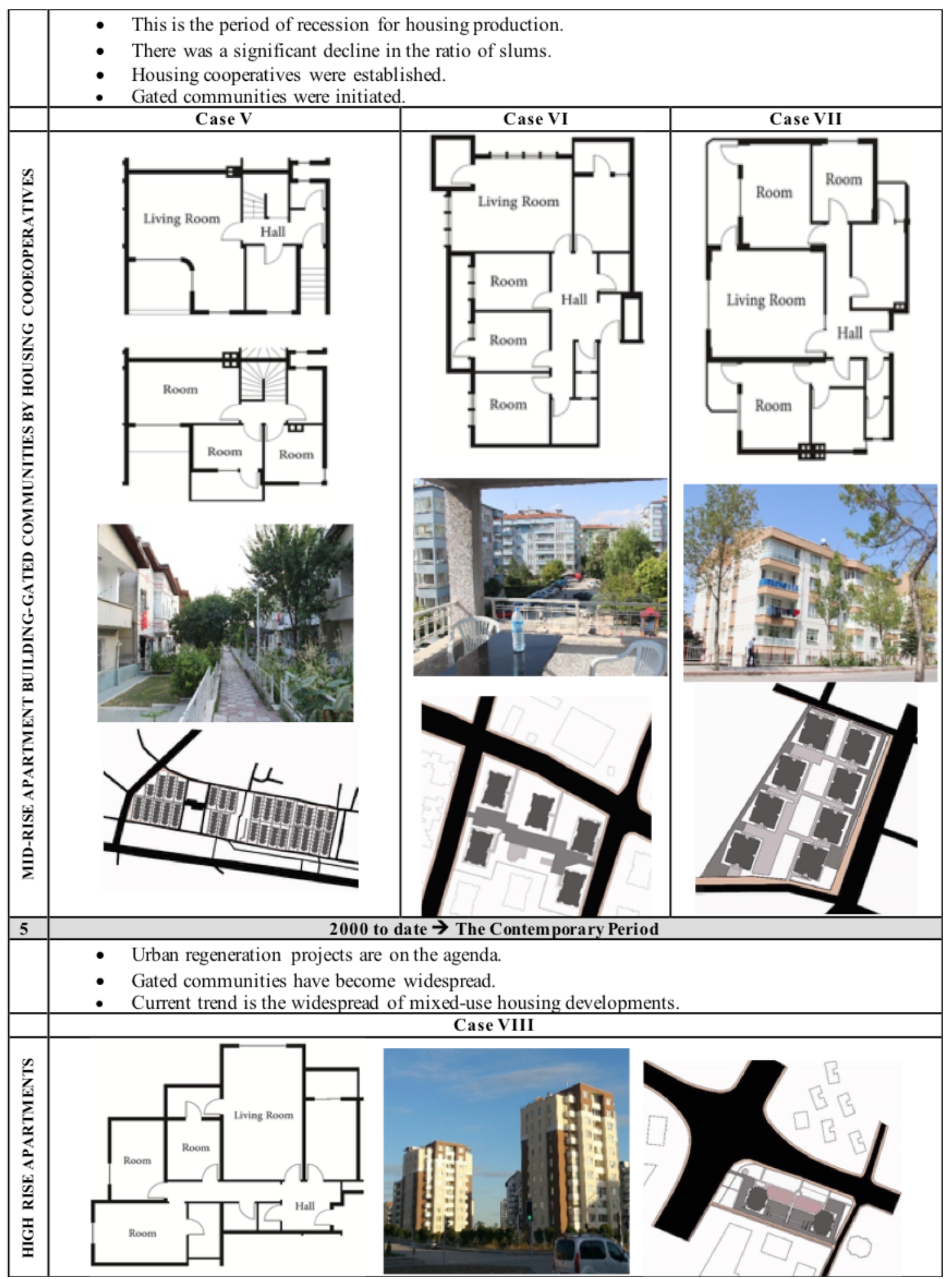

Table 2: Morphological periods, changing housing trends, case selection (Guney \& Wineman, 2008; Sey, 1998; Altaban, 1998; Guzey 2009, Keles et al., 2009). 
central hall (Case II) introduced in the 18th century but became widespread in the 19th century (Bozkurt, 2009). The rooms in the former are arranged along the two sides of the hall and therefore the hall is internally located (Bozkurt, 2009). In the later, the hall is located centrally between the other functional areas. The house layouts are slightly different, but their associated streets and neighbourhoods share the same spatial characteristics. In both cases, the number of rooms and the size of the houses vary depending on their residents' needs, family size and socio-economic situations. Thus, there is no fixed/rigid house plans for them.

Then, in the following morphological period (The Early Republican Period), garden city houses were introduced into Ankara as a low-density housing solution after the WWI. Bahcelievler housing development (Case III) planned by Hermann Jansen in 1934 in Ankara was the first garden city housing in Turkey and has been used until the 1950s (Kansu, 2009). The settlement mainly consists of two-floor single family detached housing units linearly arranged along the street, with a level entry onto the lower floor where the living room and the kitchen were located, the upper floor is the bedrooms. They are located close to the street line in their individual plots. The entrance to the houses is through a front garden. Compared to the traditional street network, the street layout is more regular and rigid. The development has undergone rapid transformation after 1950s.

The years following the 1950s (the Modernisation period) saw a dramatic increase of the population in Ankara (Keles et al., 2009). With changes in regulations, low/medium rise apartment buildings (Case IV) have become widespread in Ankara (Altaban, 1998) and largely replaced the garden houses. Soon after, Ankara was named 'the city of apartment blocks' in the 1960s (Altaban, 1998). The 1950s apartment buildings are mainly three storey housing developments with high land coverage. Their spatial layout resembles traditional houses in terms of the central location of the main living area (hall), and is similar to the garden houses regarding plot/street design. Currently, in many streets, most of the apartments have been knocked down and replaced by the new apartment buildings. However, the new formation also follows the previous plot pattern even though they slightly vary in their building footprint size.

Despite a high demand of affordable housing in the late 1970s (Coban, 2012), only the houses for mid- and high-income groups were constructed by private developers who were the dominant actors $(70 \%)$ in the housing market in the 1980s (Burkay, 2006). The urban poor remained in slums which spread continuously in many areas of the city (Erman, 2001). Without adequate financial support from the government, the houses constructed by housing cooperatives were also for mid- and high- income groups (Sey, 1998). One of the examples is the housing cooperative 'Batikent' in Ankara (Coban, 2012). Three housing developments from the Batikent project are selected to examine the typological characteristics in the Liberalisation period. One is a low-rise, high-coverage mass housing development built in 1988 (Case V). It consists of 288 single-family terrace housing units arranged adjacent to each other and backto-back. The individual units are two/threefloor and arranged along the pedestrian streets. The houses face either west or east and the routes lay north to south. Their front gardens serve as a buffer zone between the housing unit and the pedestrian street. The second one is an example of a mid-rise, medium-coverage mass housing development from the early 1990s (Case VI). The borders of the site are clearly defined, and the site access is partly restricted by the site administration. There are five identical buildings with five floors and each floor consists of four flats. Within the borders of the site, there is a car parking, a playground area and a meeting point. The third one is also a mid-rise, medium-coverage mass housing development from the early 1990s (Case VII). Like Case VI, the site is gated and the access is partly restricted by the site administration. Within the site, there are eight identical blocks linearly arranged in two rows. The blocks are five floors, and each floor consists of four flats. The development provides limited number of car parking but many sitting/resting facilities with well-managed vegetation and gardening. Not until the 2000s (the contemporary period), 
affordable housing was constructed at a large scale in Ankara to replace slums and squatter houses (Burkay, 2006). Housing cooperatives were not active anymore in later years (Coban, 2012), and private developers and the Public Housing Administration were the main actors (Guzey, 2009). High-rise apartment buildings became the urban norm in the contemporary period. The layouts of these new apartment buildings were inspired by international models and completely different from the previous house types of Turkey. Due to the tension among different social groups, the high-rise apartments are mostly gated (Coban, 2012). Commercial and other uses were incorporated in such gated developments, often on the lower floors. Case VIII is one of the mixed-use gated housing communities. It consists of two 12 -floor apartment buildings accommodating 80 flats in total. A car park and a commercial development are located between the two buildings.

\section{The analyses of types according to typologi- cal frame at the three scales}

This study has conducted 13 pairwise comparisons between the above described cases through the spatial characteristics defined earlier in the typological frame at the three scales (Table 1). The pairwise comparisons have been done in a chronological order. One case in one morphological period is compared to the newer cases that are either in the same morphological period or in the following morphological period. Figure 1 shows the results of these comparisons.

\section{Defining typological process according to the pairwise comparisons}

According to the pairwise comparisons of the spatial characteristics in Figure 1, the relation between the cases is defined as continuity where all or most of the spatial characteristics continued in the following case, as seen between Case I and Case II. When the cases have gone through partial changes but some characteristics have continued or partly continued, the transformation is defined as partial continu- ity. Where all or most of the spatial characteristics have discontinued in the following case, the transformation is defined as mutation. Given this, the relative relations defined between the cases at the three scales are summarised in Figure 2.

The analysis showed that mutation was observed at the three scales between the first two morphological periods. The gradual transformation of traditional Turkish houses (Case I and Case II) has stopped with the introduction of the garden houses (Case III). At the building scale, after Case III, the house types continuously transformed till today with partial changes. At the street scale, following Case III, typological process continued during the next two periods, then dramatic changes have occurred and typological process has stopped. At the neighbourhood scale, the gradual transformation occurred from Case III to Case V. The rest of the cases mainly showed mutational changes.

\section{Conclusion}

Typological process is often considered as a fruitful approach to study the evolution processes of building types (Barke, 2011), since reconstructing typological process can help one discover "the rules and laws through which the urban landscape develops and to which any new design could then be related" (Feng, 2014). Currently, there is an increasing interest in sustaining historical continuity in architectural and urban design practice because it benefits residents' sense of place and socio-cultural sustainability. It is widely believed that typological process can inform the management of changes and conservation of the urban built environments (Barke, 2011). However, there is less clarity in its empirical validation because of the issues derived from the judgement on the degree of transformations, the obscurity in the typological frame defining the certain spatial characteristics and the lack differentiation between the different place scales.

This study has attempted to address such issues in the Turkish housing context and has offered a methodological measure to define typological process. It analysed eight Turkish 

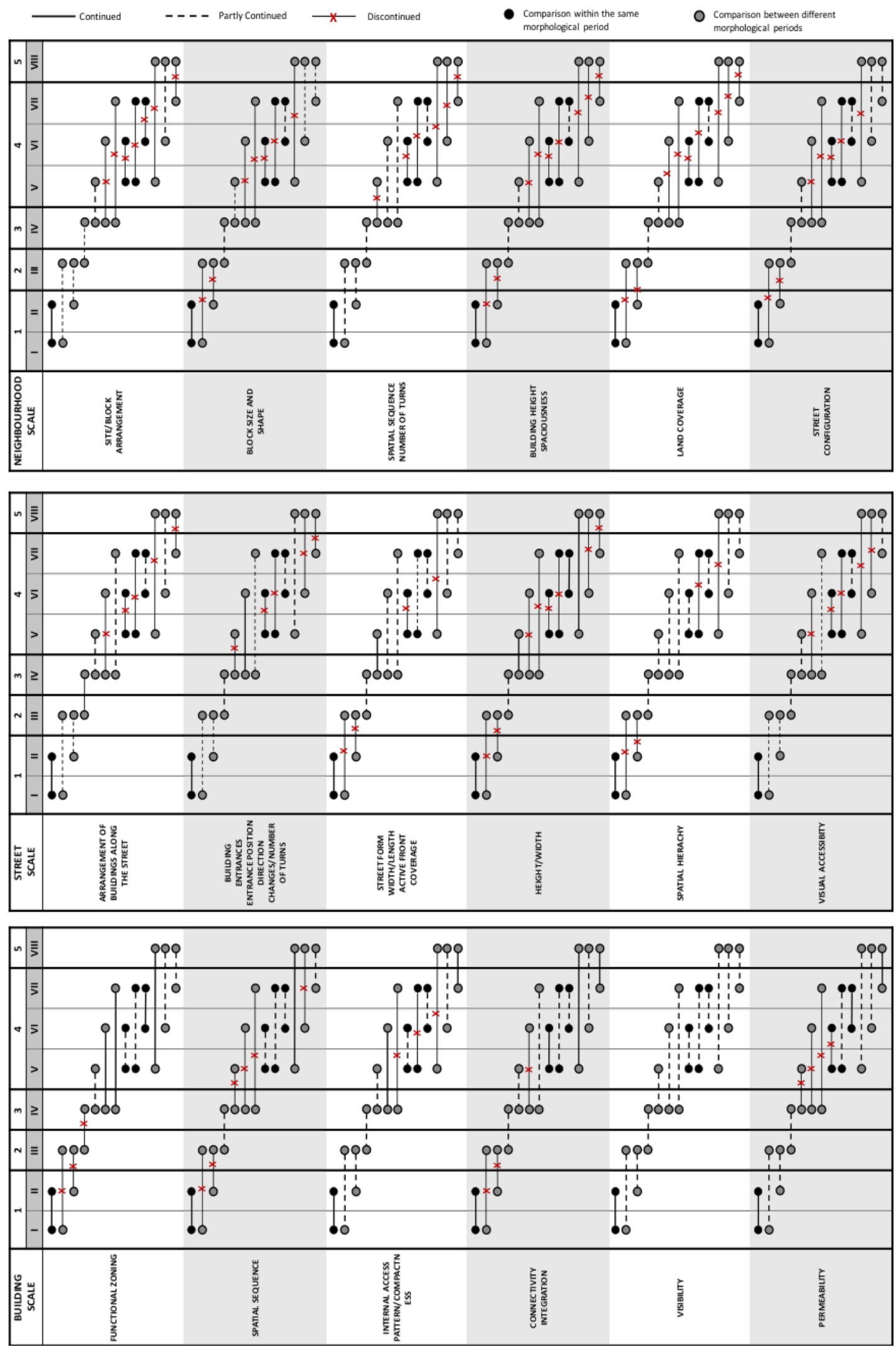

Figure 1. Pairwise comparisons of the cases at the building, street and neighbourhood scales 
TYPOLOGICAL PROCESS ANALYSIS

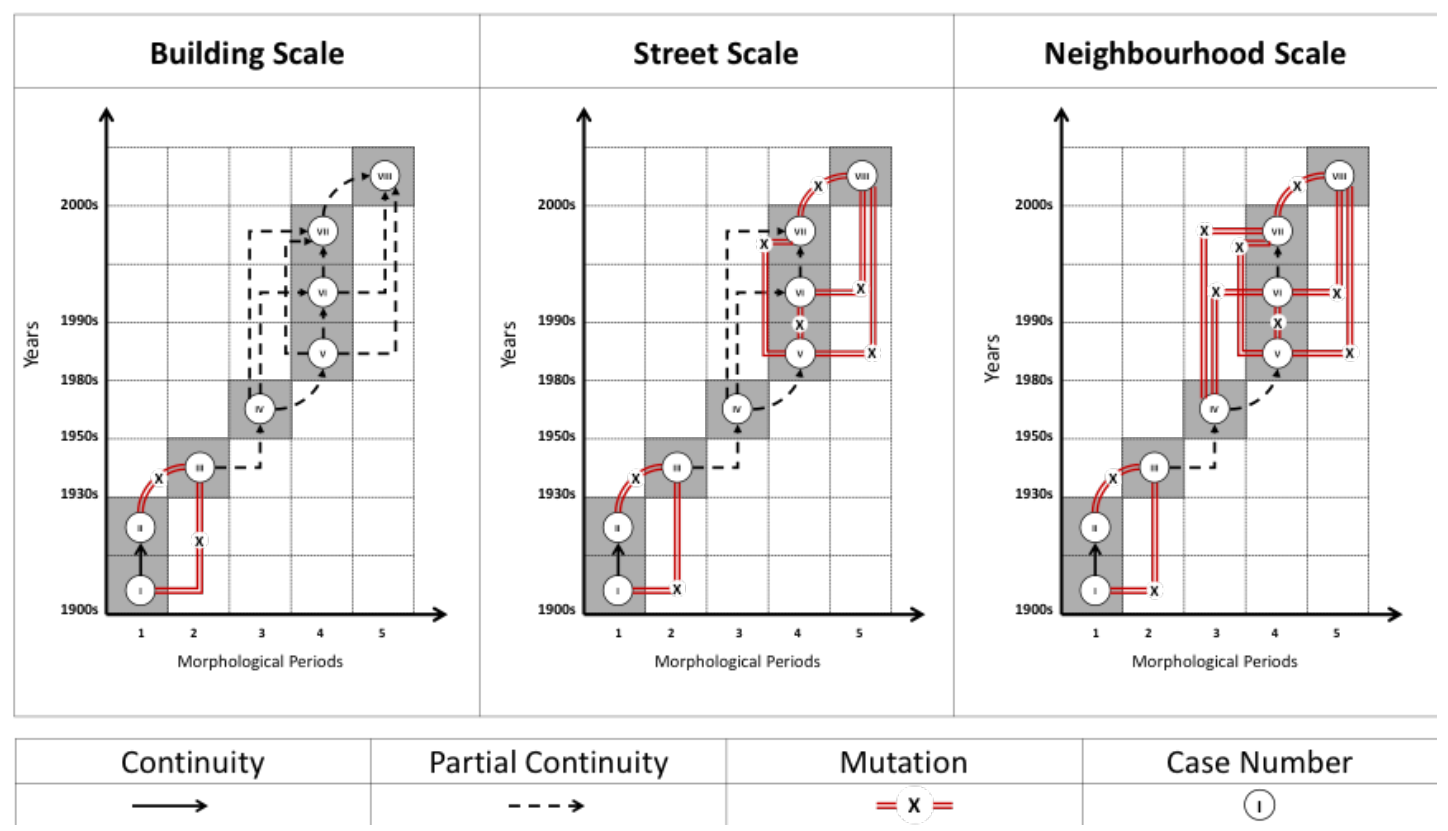

Figure 2. Typological process analyses at three scales

housing typologies representing different housing design concepts of the five morphological periods in Ankara according to the typological frame making the spatial characteristics needed to be considered for the definition of the spatial types at the building, street and neighbourhood scales. The study identified three degrees of changes between the cases: continuity, partial continuity and mutation and the former two are considered as typological process. The study showed that typological process has stopped and started again during the transformation process of Turkish house form. However, the degrees of change were not consistent at the three scales. Typological process was more prominent and lasted longer at the building scale. At this scale, the typological process stopped after the first morphological period and restarted again in the third morphological period. It continued to date with partial changes. More dramatic changes in typological characteristics (mutations) were observed at larger scales. It showed that while at one level typological process is observed, it may not be observed at another level.

The proposed study of typological process through the comparison of a set of spatial characteristics at the related multiple scales is an important contribution to the knowledge because there is no consensus regarding what elements of the built environment should be studied at what scales in relation to typological process. These characteristics extracted from literature as important morphological characteristics are operational, therefore might vary depending on different spatial typologies, place scales and cultures. However, they can still serve as the basis for further research to adopt or revise according to their specific research objectives and can be extended by including other typological and morphological elements of the built form, which needs to be studied further. The three degrees of changes identified in the transformation process are also new to the literature. By comparing the numbers of similarities and differences in the spatial characteristics, the degrees of changes are rigorously and clearly defined which will inform the establishment of typological process.

Overall, although the proposed approach in this study is demonstrated through the Turkish context, the methodology is applicable to other cities and countries and to help the understanding of their transformation processes. Nevertheless, the typological frame, morphological periods and degrees of change can be adjusted according to specific research objectives. 


\section{References}

Alexander, C., Ishikawa, S., Silverstein, M., Jacobson, M., Fiksdahl-King, I. and Angel, S. (1977) A Pattern Language: Towns, Buildings, Construction. New York: Oxford University Press.

Altaban, O. (1998) 'Cumhuriyetin Kent Planlama Politikaları ve Ankara Deneyimi’. In: 75 Yılda Değişen Kent ve Mimarlık (City and Architecture changing in 75 years). İstanbul: İş Bankası Kültür Publishing, 4164.

Barke, M. (2011) 'The Lifespan of A Typological Form? Los Corales De Malaga, Spain'. Urban Morphology, 15(1), 21-38.

Bozkurt S. G. A. (2009) Investigation at instance of Safranbolu Houses of Indoor Montage in Ottoman Domestic Architecture in 19th Centruy, Master's Dissertation, Istanbul Kultur University, Faculty of Fine Arts and Design.

Burkay, H. O. (2006). Social Policy of Urban Transformation:Social Housing Policies in Turkey from the 1980s to Present. Master's Dissertation. The Ataturk institute for Modern Turkish History, Bogazici University.

Caniggia, G. \& Maffei, G. L. (2001) Architectural Composition and Building Typology. Firenze: Alinea Editrice.

Chen, F. \& Thwaites, K. (2013) Chinese Urban Design: The Typomorphological Approach. Surrey: Ashgate.

Coban, A. N. (2012) 'Housing Policies from the Proclamation of the Republic to the Present'. SBF Dergisi (Journal of Faculty of Political Sciences), 67(3),75-1 08.

Corsini, M. G. (1997) 'Residential building types in Italy before 1930: the significance of local typological processes'. Urban Morphology, Volume 1, 34-48.

Dufaux, F. (2000) 'A new world from two old ones: the evolution of Montreal's tenements, 1850-1892'. Urban Morphology, 4(1), 9-19.

Erman, T. (2001) 'The Politics of Squatter (Gecekondu) Studies in Turkey: The Changing Representations of Rural Migrants in the Academic Discourse'. Urban Studies, 38(7), p. 983.

Feng, Q. (2014). A Typo-morphological
Enquiry into the Evolution of Urban and Architectural Forms in the Huangpu District of Shanghai, China, Montreal, Master's Dissertation, Concodia University.

Gauthiez, B. (2004) 'The history of urban morphology'. Urban Morphology, 8(2), 7189.

Gokce, D., (2017) 'An Empirical Investigation of the Interplay between Typo-Morphological Transformation of Historic House Form and Sense of Place'. Unpublished PhD Thesis, Department of Architecture, University of Liverpool.

Gokce, D. \& Chen, F. (2016) 'Does typological process help to build a sense of place?', Urban Morphology, 20(1), 66-69.

Gokce, D. \& Chen, F. (2017) 'Sense of Place in the Changing Process of House Form: Case Studies from Ankara, Turkey'. Environment and Planning B: Urban Analytics and City Science. DOI.10.1177/0265813516686970

Gu, K., Tian, Y., Whitehand, J. \& Whitehand, S. M. (2008) 'Residential Buildings Types As An Evolutionary Process:The Guangzhou Area, China'. Urban Morphology, 12(1), 97-115.

Guney, Y.I. \& Wineman, J. (2008) 'The Evolving Design of 20th Century Apartments in Ankara'. Environment and Planning B: Planning and Design, 35, 627-646.

Guzey, O. (2009) 'Urban regeneration and increased competitive power: Ankara in an era of globalization'. Cities, 26, 27-37.

Gygax, F. (2007) 'The Morphological Basis Of Urban Design: Experiments In Giudecca, Venice'. Urban Morphology, 11(2), 111-125.

Keles, R., Hamamci, C. \& Coban, A. (2009) Cevre Politikasi (Environmental Politics). Ankara: Imge.

Kropf, K. (1993) The Definition of Built Form in Urban Morphology, PhD Thesis, University of Birmingham.

Kropf, K. (2006) 'Crisis in the typological process and the language of innovation and tradition'. Urban Morphology, 10(1), 70-77.

Kropf, K. (2009) 'Aspects of urban form'. Urban Morphology, 13(2), 105-20.

Lynch, K. (1960) The Image of City. Cambridge: The MIT Press.

Maretto, M . \& Scardigno, N. (2016) 'Muratorian Urban Morphology: The Walled 
City Of Ahmedabad'. Urban Morphology, 20(1), 18-33.

Moudon, A. V. (1994) 'Getting to Know the Built Landscape: Typomorphology’. In: Ordering Space: Types and in Architecture and Design. New York: Van Nostrand Reinhold, 289-311.

Oliveira, V. Monteiro, C. \& Partanen, J., (2015) 'A Comparative Study of Urban Form'. Urban Morphology, 19(1), 73-92.

Racine, F. (2016) 'Developments In Urban Design Practice In Montreal: A Morphological Perspective'. Urban Morphology , 20(2), 122-37.

Rapoport, A. (1969) House Form and Culture. London: Prentice-HALL, INC.Englewood Cliffs, N.J.

Ryan, B. D. (2006) 'Morphological Change Through Residential Redevelopment: Detroit, 1951-2000'. Urban Morphology, 10(1), 5-22.

Scheer, B. C. (2016) 'The epistomology of urban morphology'. Urban Morphology, April, 20(1), 5-17.

Sey, Y. (1998) 'Housing in Republican period'. In: The Changing City and Architecture in 75 years. Istanbul: Tarih Vakfi Press, 273300 .

Whitehand, J., Gu, K., Conzen, M. P. \& Whitehand, S. M. (2014) 'The typological process and the morphological period: a cross-cultural assessment'. Environment and Planning B: Planning and Design, 41, 512-533. 